\title{
Exercising abilities
}

\section{J. Adam Carter ${ }^{1}$}

Received: 3 March 2018 / Accepted: 22 April 2019 / Published online: 29 April 2019

(c) The Author(s) 2019

\begin{abstract}
According to one prominent view of exercising abilities (e.g., Millar in Acta Anal 24(4):223-236, 2009), a subject, $S$, counts as exercising an ability to $\phi$ if and only if $S$ successfully $\phi$ s. Such an 'exercise-success' thesis looks initially very plausible for abilities, perhaps even obviously or analytically true. In this paper, however, I will be defending the position that one can in fact exercise an ability to do one thing by doing some entirely distinct thing, and in doing so I'll highlight various reasons (epistemological, metaphysical and linguistic) that favor the alternative approach I develop over views that hold that the exercise of an ability is a success notion in the sense Millar maintains.
\end{abstract}

Keywords Virtue epistemology · Ernest Sosa · Virtue reliabilism · Performance epistemology · Ability

\section{Ability exercise and success}

Suppose you have the ability to beat Garry Kasparov at chess. When do you count as exercising or manifesting that ability? Is earning a hard-fought draw against Kasparov good enough? What about 50 draws in a row?

According to proponents of the EXERCISE-SUCCESS thesis, 50 draws, or even a million draws, against Kasparov is not good enough. You've got to actually beat him. According to this thesis:

EXERCISE- SUCCESS: the ability to $\phi$ is exercised or manifested if and only if one successfully $\phi$ s. $^{1}$

\footnotetext{
1 Millar (2009, p. 230).

J. Adam Carter

adam.carter@glasgow.ac.uk

1 COGITO Epistemology Group, University of Glasgow, Glasgow, Scotland, UK
} 
As Millar (2009), a champion of this thesis, puts it, "There is no gap between manifestation and success. The manifestation of an ability is the subject's doing what the ability is an ability to do" (2009, p. 227).

For Millar's own purposes, the importance of this thesis is mainly epistemological. For if (as he argues) perceptual recognitional abilities are abilities to know, then there is no gap between exercising these abilities and gaining knowledge. ${ }^{2}$ But the matter of whether the EXERCISE-SUCCESS thesis is true bears relevance generally for the philosophy of ability, as well as for other areas of philosophy-including debates about intentional action, perceptual experience, and even free will ${ }^{3}$ — where the notion of exercising ability is relied on to do explanatory work. ${ }^{4}$

In what follows, I will argue that EXERCISE-SUCCESS is false. There are counterexamples that demonstrate this, and these counterexamples, I'll show can't be convincingly deflected or otherwise explained away; moreover, behind the counterexamples lie deeper problems facing EXERCISE-SUCCESS, problems that concern aspectual classification as well as ability refinement and training. In place of EXERCISE-SUCCESS, I'll offer an alternative fallibilist account of ability exercise, one that avoids the problems that face EXERCISE-SUCCESS. On the view I propose, it is not only possible, but relatively common, to exercise an ability to do one thing by not doing that thing, and instead, by doing something else entirely.

\section{Three counterexamples to exercise-success}

\section{Consider the following three cases:}

POLE VAULT: Paul is hoping to make his high-school pole vaulting team. In order to qualify, Paul must demonstrate that he has the ability to jump over the competition bar set at 10ft. Paul's dishonest nemesis told Paul the competition bar for tryouts was three feet higher-13ft_-in an effort to dissuade Paul from attempting to make the team. Paul nonetheless showed up to tryouts and, setting the bar to $13 \mathrm{ft}$ rather than $10 \mathrm{ft}$, proceeded to jump over the bar (impressing his coach and his nemesis).

ENDER'S GAME: Ender Wiggin is a tactical genius when it comes to directing battles in a computer simulator, in which he believes he is being tested against merely

\footnotetext{
2 Lisa Miracchi holds a similar, but distinct, thesis concerning ability manifestation. On her view, propositional knowledge is an exercise of a competence to know (Miracchi 2015, p. 41). More specifically, on her proposal (i) 'a competence to know is manifested just in case its manifestation conditions obtain' (2015, p. 46) and (ii) '[t]he manifestation conditions of [sic. a competence to know] are whatever operations of subpersonal cognitive mechanisms and external conditions together (against a background of possession of [sic a competence to know]) constitute a particular case of knowing that $\mathrm{p}$ in the way characteristic of the competence [...] (2015, p. 25)'. That said, Miracchi holds that abilities can be exercised degenerately, despite being such that they are manifested only when one does what the ability is an ability to do. From Miracchi's perspective, then, the exercise-success thesis is strictly false, but would come out true if we removed 'exercised' and kept just 'manifested'. (Millar, by contrast, takes these two notions to be equivalent). Thanks to an anonymous referee at Synthese for drawing attention to this point.

3 See, for example, Vihvelin (2004); cf., Vetter (2016).

4 For an overview of how the notion of exercising an ability bears relevance to debates about the nature of intentional action and perceptual experience, see Sosa (2015, Ch. 1).
} 
virtual opponents controlled by Commander Mazer. Mazer informs Ender, after Ender wins the final battle, that the battle was in fact real; Ender, it turns out, had been unbeknownst to him switched by Mazer from fighting simulated opponents to directing real human spacecraft by way of an instantaneous communicator, and in doing so, Mazer informs him he's won the war. ${ }^{5}$

LINGUIPHILE SPY: George Smiley is a British MI6 secret intelligence agent under interrogation by the Foreign Secretary's office for leaking documents to a foreign power. It is known that whoever leaked the documents was fluent in the Basque language. Smiley, guilty of the crime, insists falsely that he doesn't know Basque. The government has a plan: Smiley, hooked up to an fMRI machine, is shown a page including many gibberish fake words, and some genuine Basque words; for a given word, if Smiley understands it, the fRMI will detect neural activity in his cerebral cortex unlikely to be present if he is looking at gibberish. Fortunately, Smiley has good peripheral vision, and through this good peripheral vision he can tell that an inscription is a Basque word before he finishes reading it. And so, whenever what Smiley can tell is a Basque-looking word begins to come into into his peripheral vision, he quickly — as a way to beat the system — averts his eyes to a 'safe' gibberish word, preventing his brain from lighting up in a way that would be detected by the sensors. He is released, having deceived his interrogators. ${ }^{6}$

First, a brief comment about each case, respectively. Firstly, regarding POLE VAULT. Has Paul exercised his ability to jump over the bar set at 10ft, by successfully jumping over the bar set at $13 \mathrm{ft}$ ? Granting that the very point of the jump was to demonstrate - by literally exercising in controlled conditions - the ability to jump over the $10 \mathrm{ft}$ bar, it would seem pointless for the coach to (having witnessed what Paul just did) proceed to then request Paul jump over the bar at 10ft in order to 'demonstrate that he can jump over the bar at 10ft'. But if this is right, then it looks like EXERCISE-SUCCESS is false: Paul has exercised his ability to jump over the bar set at 10ft even though he did not jump over the bar set at $10 \mathrm{ft}$ (his nemesis saw to that!)

Consider now ENDER'S GAME. Intuitively-and indeed, this is the casual gloss that is common amongst folk descriptions of the Ender's Game plot-Ender is using his ability to direct battles in a computer simulator to direct a battle that is in fact not simulated, but real. Putting things this way is actually explanatorily important: it's not just that Ender is exercising an ability to direct real battles (though I will remain neutral on this point.) EXERCISE-SUCCESS, however, is unable to account for the intuition that Ender is exercising here the ability he has (indeed, cultivated and refined) to direct simulated battles.

Likewise, for George in LINGUIPHILE SPY. Intuitively, George is using his ability to understand Basque word meanings (the understanding of which would in the circumstances described have got him busted) to do something other than to understand Basque word meanings-viz., to avoid reading and understanding Basque words. The EXERCISE-SUCCESS principle implies, counterintuitively, that George could not exercise such an ability without getting busted (e.g., without successfully understand-

\footnotetext{
5 This case summarizes the plot of Orson Scott Card's 1985 novel Ender's Game (Card 1985).

6 This uses a character from John le Carré's Tinker Tailor Soldier Spy (1974).
} 
ing the Basque words, an outcome that would have alerted George's interrogators by triggering the FMRI scanner).

Of course, the proponent of EXERCISE-SUCCESS is not going to take these counterexamples lying down. Here is the plan. In Sect. 3, I consider a general strategy of reply that appeals to considerations to do with 'ability implication'—one that Millar has already anticipated in connection to POLE-VAULT-style cases-and show that it doesn't work in that case and won't work elsewhere. Then, in Sect. 4, I suggest some deeper problems with EXERCISE SUCCESS, problems that go beyond the counterexamples themselves, and which reveal some fallibilist lessons about ability exercise. In Sect. 5, I propose an alternative to EXERCISE SUCCESS, one informed by the fallibilist insights from Sect. 4, and show how this alternative avoids the initial counterexamples raised to EXERCISE SUCCESS. In Sect. 6, I consider a range of objections to the proposal I advance and reply to each anticipated objection.

\section{Ability (non)-implication to the rescue?}

Perhaps the proponent of EXERCISE-SUCCESS has a neat strategy for dealing with all three counterexamples in one fell swoop. This is in fact what Millar suggests when anticipating POLE VAULT-style cases, ${ }^{7}$ which he thinks are, ultimately, unproblematic for EXERCISE-SUCCESS.

To appreciate Millar's reasoning here, consider first a principle he proposes, one that states the conditions under which the possession of one ability implicates the possession of another distinct ability.

ABILITY IMPLICATION: An ability to $\phi$ implicates an ability to $\psi$ if and only if necessarily, if one has the ability to $\phi$ then one has the ability to $\psi$.

Millar presumably has in mind cases like the following as examples of ability implication: if we substitute 'walk on Hesperus' for $\phi$ and 'walk on Phosphorus' for $\psi$, then ABILITY IMPLICATION says possessing the ability to walk on Hesperus implicates the ability to walk on Phosphorus because, necessarily, one has the ability to do the former if one has the ability to do the latter, because doing one thing is doing the other. ${ }^{8}$

Consider accordingly Millar's (2009, p. 230, fn. 8) envisioned modification of EXERCISE-SUCCESS, framed in terms of ability implication.

\footnotetext{
7 Millar's fn. 8, p. 230, engages with a version of this example I'd posed to him at the 2009 Bled Epistemology Conference in Bled, Slovenia.

8 One might wonder whether the principle could be objected to on the grounds that ability attributions generate referentially opaque contexts_-viz., one might embrace a principle like the following: $\diamond \exists s \exists \phi \exists \psi$ (s has the ability to $\phi$ yet does not have the ability to $\psi$, although $\phi$-ing is necessarily equivalent to $\psi$-ing). But the principle is safe from this criticism as ability attributions (unlike, perhaps, know-how attributions) do not generate opaque contexts. Williams $(2008, \S 2)$ makes this point by the following examples: 'Since Lois has the ability to contact Clark, she has the ability to contact Superman, although she might not know that she has the latter ability. Likewise Stan has the ability to make equiangular triangles (by making equilateral triangles) although he does not know that making equilateral triangles is a method of making equiangular triangles'.
} 
EXERCISE-SUCCESS $*$ : The ability to $\phi$ is exercised or manifested if and only if one either $\phi \mathrm{s}$ or does something the ability to do which is implicated by the ability to $\phi{ }^{9}$

Millar's position is that it is, on closer inspection, not plausible that an example like POLE VAULT is going to force abandoning EXERCISE-SUCCESS for something like EXERCISE-SUCCESS* because it is not plausible that the ability to jump over the higher bar really does implicate (in the sense of ABILITY IMPLICATION) the ability to jump over the lower bar, even if it indicates such an ability. As he puts it:

Some weird contingency might prevent one who has ability A from having ability B. Where there is no such contingency one might still feel there is some sense in which a manifestation of ability A could be a manifestation of ability B. But this sense might just be that some manifestations of ability $\mathrm{A}$ as a matter of fact indicate that the subject has ability B (Millar 2009, p. 230, fn. 8).

Millar is of course right that a weird contingency-he doesn't specify just what-could prevent one who has the ability to pole vault over the $13 \mathrm{ft}$ bar from jumping over the bar set at 10ft. Paul, our pole vaulter, might for all that's been said have a specific kind of scotoma-viz., a lack of light-detecting photoreceptor cells on the optic disc of the retina so placed that close-range objects at 10ft, but not 13ft, are obfuscated in a way that impedes jumping performance. But let's simply suppose no such weird contingency actually is present. Should the fact that such a weird contingency could be present lead us to deny (as per Millar's ABILITY IMPLICATION principle) that Paul's ability to jump over the bar set at $13 \mathrm{ft}$ implicates the ability to jump over the bar set at 10ft?

If no, then it looks like EXERCISE-SUCCESS must be revised (at least, to EXERCISE-SUCCESS*). But if yes, then, on the assumption that the possibility in question is logical or metaphysical possibility, it turns out that there's a straightforward explanation why POLE VAULT isn't a case of ability implication — and that's that the ability implication principle will, at least on Millar's thinking, never come out true in a case where the abilities at issue are distinct abilities. After all for any genuinely distinct pair of abilities $a$ and $b$-abilities with different possession conditions-which one has, ${ }^{10}$ it could have been that one lacked $b$ despite possessing $a$, given that a (perhaps very) weird contingency could have prevented one who has $a$ from having $b .{ }^{11}$ But if ABILITY IMPLICATION is unsatisfiable whenever the abilities at issue are distinct, then this would mean that EXERCISE-SUCCESS* would simply collapse into Millar's original EXERCISE-SUCCESS principle; and then the question of whether POLE VAULT (or any would-be counterexample) forces a modification from EXERCISE-SUCCESS to EXER-

\footnotetext{
9 Ibid., 230, fn. 8.

10 The ability implication principle is not trivially false for non-distinct abilities. Two abilities are distinct iff they have different possession conditions, otherwise, they are non-distinct. In the case of non-distinct abilities, the ability implication principle is however trivial in that it just tells us that an ability to $\phi$ implicates an ability to $\psi$ when $\phi$ and $\psi$ are non-distinct-viz., an ability to $\phi$ implicates an ability to $\phi$.

11 Granted, one might press back and claim that, even in the case of abilities with distinct possession conditions, it might be that possessing one is such that, necessarily, by possessing it, one possesses the other. For the present dialectical purposes, I'm happy to grant Millar's broadly Humean take on this issue.
} 
CISE-SUCCESS* rests on the false presupposition that the EXERCISE-SUCCESS* principle that Millar envisages is in fact a substantive modification of EXERCISE-SUCCESS.

In sum, then, it looks like the strategy canvassed for saving EXERCISE-SUCCESS from the counterexample raised by POLE VAULT doesn't ultimately defuse the case as a counterexample to EXERCISE-SUCCESS. And if that's right, then there's no reason to think such a strategy will be useful for dealing with the other kinds of counterexamples raised either.

\section{Deeper worries}

In this section, I want to suggest that the problems that face EXERCISE-SUCCESS run deeper than the mere inability to accommodate counterexamples such as those in Sect. 2 might indicate.

Let's take as a starting point a simple idea: that exercising an ability must at the very least involve a doing. (If it did not, there would be difference between possessing and exercising an ability). A question that has exercised some theorists is whether the kind of 'doing' that exercising an ability involves must always be accompanied by an intention, a view originally held by Moore (1911) and which has been more recently defended by Vihvelin (2004). ${ }^{12}$

Despite initial plausibility (e.g., we oftentimes intend to bring about some outcome when exercising an ability), there are good reasons to think the answer here is 'no'. Vetter (2016), for example, highlights as problematic ${ }^{13}$ for this idea at least two kinds of cases: (i) cases where one seems to exercise complex skills by doing things that are not apparently accompanied any intentions or choices (consider what one does when one almost loses balance on a bicycle, and quickly and skilfully moves to correct course $^{14}$ ); and (ii) subintentional cases, such as the following:

I just scratched my nose while thinking about this sentence. I did not try or decide to scratch my nose, I did not form any relevant intentions; I just did it. My scratching my nose was none the less an exercise of my motor abilities-it involved, among other things, a coordination of movements in my arm and fingers that was clearly the manifestation of an ability.

To the extent that the kinds of cases Vetter raises are compelling, it's probably a wise idea not to simply assume that exercising an ability must involve-in addition to a doing - an accompanying intention, even if intentions generally correspond with ability exercise (this is a point we will return to in Sect. 6). Interestingly, though, even the minimal and uncontroversial idea that exercising an ability, unlike merely possessing an ability, involves a doing — regardless of whether the doing is accompanied by an

\footnotetext{
12 For a critique of Vihvelin's position, referred to as 'New Dispositionalism', see Vetter (2016).

13 See Steward (2012) some similar criticisms.

14 As Vetter puts it, "In riding a bicycle, I perform a complex series of movements that are correlated with proprioception, perception of my surroundings, and so forth. I see a car coming; I slow down and keep to the right side of the road. I almost lose my balance on a wet road; I perform a number of movements that keep me from falling. I do not have the time or the need to choose, try, intend, or decide to do those things; I just do them".
} 
intention - turns out to make some trouble for, or, at least, place a serious explanatory burden on, the proponent of EXERCISE-SUCCESS.

Here's the worry: doing anything involves some kind of occurrence, where an occurrence has a temporal beginning and lasts a duration, the duration of the exercising. According to Millar, exercising an ability is a particular kind of occurrence, namely that of the subject's doing what the ability is an ability to do. Now, here's where things begin to get dicey for champions of EXERCISE-SUCCESS: given that the kind of doing (or more generally, performance) that characterises exercising abilities is supposed to be a success notion, then unless we actually go on and accomplish what the ability is an ability to do, and not merely if we perform the activity with the aim of accomplishing, we aren't actually exercising the relevant ability.

Why is this a problem, as opposed to merely a description of what is a priori entailed by EXERCISE-SUCCESS? At this point it will be helpful to situate the EXERCISE-SUCCESS thesis with reference to the Vendler-Kenny aspectual classification of verb types ${ }^{15}$; given that on EXERCISE-SUCCESS model exercising ability is, necessarily, a kind of accomplishment rather than merely an activity, the aspectual properties of exercises of ability should line up with aspectual properties of accomplishments rather than merely activities, whenever these come apart. ${ }^{16}$

And the aspectual properties of accomplishments and activities do come apart in at least one key way: what Vendler (1957) calls their temporal homogeneity. It is an essential aspectual property of activities that they are temporally homogeneous in that, as they unfold over time, any part of the process is of the same nature as the whole. As Vendler (1957) puts it:

If it is true that someone has been running for half an hour, then it must be true that he has been running for every period within the half-hour (1957, pp. 145-146).

The same, however, is not the case with accomplishments-viz., running a mile as opposed to merely running. It's not true of one who has run a mile (say, in 4 min) that he has 'run a mile during any period which is a [...] part of that time [...]' (146). The same goes for other kinds of accomplishments, for example, drawing a circle or writing a letter. As Vendler sums up this difference in temporal homogeneity between activities and accomplishments:

It appears then that running and its kind go on in time in a homogeneous way; any part of the process is of the same nature as the whole. Not so with running a mile or writing a letter; they also go on in time, but they proceed toward a

\footnotetext{
15 For a helpful overview of this model, see Mourelatos (1978). In recent work, Matthew Chrisman (2012) has appealed to the Vendler-Kenny model in order to call into question the thesis that a belief can be fruitfully modelled as a kind of performance; for a recent reply to Chrisman on this point, see Rohrbaugh (2015).

16 It is worth noting that even activities like 'riding a bike' are such that, on Millar's view, one exercises the ability to do these things if and only if one does them, and not if merely begins, or attempts to, do them (Millar 2009, p. 224). In this respect, Millar's view that exercising an ability is a success notion is such that it effectively treats all abilities to do activities with success standards as though they were accomplishments, in that one counts as exercising the ability to do activities with success standards only if one has in fact succeeded in doing the activity. One qualification here concerns the class of activities that essentially lacks success standards-e.g., 'aimless ambling' (Sosa 2009, p. 23). I'm not clear what to make of these cases, which are rare ones, and for the present purposes remain agnostic as to how we should theorise about them. For discussion, see Vetter (2016, p. 13).
} 
terminus which is logically necessary to their being what they are. Somehow this climax casts its shadow backward, giving a new color to all that went before (1957, p. 146, my italics).

The fact that accomplishments and activities differ in their temporal homogeneity might seem like a distinction without a difference relevant to the material adequacy of EXERCISE-SUCCESS. However, there is at least one straightforward-and somewhat awkward-implication, which is this: for if exercising an ability is just the subject's doing what the ability is an ability to do, understood as an accomplishment (i.e., a success notion) rather than merely an activity, then (oddly) - given the aspectual difference in temporal homogeneity between accomplishments and mere activities - it follows (from EXERCISE-SUCCESS) that one is not exercising the ability to $\phi$ during any time during the duration of the accomplishment of $\phi$-ing. A comparatively much more plausible thought is that the doing that is the exercising of an ability begins right when one attempts to $\phi$, something that EXERCISE-SUCCESS categorically precludes. ${ }^{17}$

If pressed here, the proponent of EXERCISE-SUCCESS, given that it identifies ability exercise with accomplishment, might (i) simply reject the Vendler-Kenny aspectual treatment of accomplishments; or (ii) accept it and then simply insist that one exercises her ability to do something only at the durationless instant that one has done that thing, and accordingly, not when one begins to do that thing. ${ }^{18}$ Neither is a very attractive option. The former would require a substantial error theory, one that explains why the received view of the aspectual treatment of accomplishments is incorrect. The latter effectively concedes that ability exercise is atemporal ${ }^{19}$; given that doings are paradigmatically temporal, this conflicts with the minimal assumption we began with, which is that exercising an ability must at the very least involve a doing if we are to retain the distinction between exercising and merely possessing an ability. ${ }^{20}$

\footnotetext{
17 It's worth registering that this way of thinking fits snugly with (though does not imply) a position in the metaphysics of powers according to which manifestations of powers are better thought of as contributors to effects as opposed to effects themselves. Though, it is beyond the scope of the present paper to explore this connection fully. For a criticism of the view that manifestations of powers are contributors to their effects, see McKitrick (2010).

18 Thanks to an anonymous referee at Synthese for suggesting this move on behalf of the proponent of EXERCISE- SUCCESS.

19 I put aside the matter of whether an atemporal being could be the author of atemporal doings. It is worth noting that, at least according to the Leibniz-Ross theory, the only kind of entity that could act atemporally is an omnipotent being. See, e.g., Pearce (Pearce 2012).

20 Interestingly, Millar indicates in places that such a result might be acceptable after all, though with some caveats. In discussing how a proponent of EXERCISE- SUCCESS can account for the fact that some abilities appear to demand reliability at some specified rate, he writes: "Suppose that I can throw a basketball into the basket from $10 \mathrm{~m}$ about $10 \%$ of the times on which I try. I exercise that ability if and only if over a series of trials, each trial comprising a sequence of throws, my success rate is roughly $10 \%$. A single success is not a manifestation of my ability. A near miss is not a manifestation of my ability either. Manifestation is doing what the ability is an ability to do and in this case that is to achieve a success rate of $10 \%$ in attempts at doing the thing in question 2009, p. 224)." This consequence might look initially acceptable in low-trials cases, but much less so otherwise. Take for example Ted Williams' baseball hitting ability. That is an ability that Williams plausibly exercised nearly every day he took the field. (His great rival Joe DiMaggio has attested to this!) The ability was also quantified: a batting average of .344. If we follow Millar and treat abilities to do something some percentage of the time as such that they are exercised only upon the conclusion of the relevant series of trials, then given that .344 is 344 hits per 1000 at bats, Williams will have exercised his
} 
But even if we set the above issue aside, there's a deeper point lurking that faces any view that encourages us to think of ability exercise in terms of accomplishment, and one that does not turn on anything to do with 'accomplishment' as an aspectual classification. In the case of motor abilities at least, the acquisition of an ability is widely thought to come in three stages: the cognitive, associative and autonomous stages (e.g., Fitts and Posner 1967), where the transition across these stages is marked by gradual improvement (viz., increased counterfactual safety across a wider range of performance situations).

But ability acquisition, as it unfolds across these learning stages, is hardly climactic, especially in the case of complex abilities, such as those we acquire and then fine tune in athletic domains. After all, even after one becomes such that she would succeed safely enough if she tried in the relevant conditions (e.g., safely enough to count as having the ability), one often continues to exercise her ability with the aim of getting better. But, at least according to one leading view of expertise (e.g., Ericsson and Pool 2016), practicing to the point of failure is not only common but (arguably) essential to improving the abilities we have, as we transition from 'good enough' to experts in certain domains. This is an idea that drives contemporary constraintsbased coaching ${ }^{21}$ — viz., in which players are encouraged to practice in much harder conditions (e.g., in which they succeed much less safely) than those in which they will likely compete. What this means is that the identification of ability exercise with accomplishment at what a given ability is an ability to do effectively diminishes the role of exercising abilities in an account of how we improve them.

Of course, an account of ability exercise can easily sidestep all of this by not thinking about exercising an ability as involving the attainment of an aim, but rather, as merely a kind of activity, one with an aim that it may or may not attain as a result of the competence's exercise. That is, an activity we can think of as proceeding toward a terminus where the actual attainment of the terminus is not logically necessary to the activity being what it is.

\section{A fallibilist alternative}

The three counterexamples, along with the discussion in Sect. 4, suggest that a plausible account of ability exercise should abandon EXERCISE-SUCCESS for FALLIBILISM.

FALLIBILISM: It is possible to exercise the ability to $\phi$ without successfully $\phi$-ing. FALLIBILISM avoids entirely the kinds of objections raised in Sect. 4 to EXERCISESUCCESS, including both those pertaining to (i) aspectual classification; and (ii) ability refinement. After all, for fallibilists, it simply isn't required of ability exercise that one successfully does the thing that the ability is an ability to do; ability exercise isn't essentially an accomplishment.

Footnote 20 continued

famous hitting ability only seven times in his $20+$ year career (!), a career that included 7706 at bats. Of course, a way around this is to define Williams' ability as not an ability to hit .344, but rather, as simply an ability to hit the ball (and reach base). And then, as per EXERCISE- SUCCESS, this is an ability that he exercises if and only if he hits the ball and reaches base. But then we're back to facing the issues raised in the present section.

21 For an overview, see Glazier and Davids (2009). 
A commitment to FALLIBILISM is, by itself, enough deflect the counterexamples from Sect. 2 in the sense that these cases are not counterexamples to FALLIBILISM as they were to EXERCISE-SUCCESS. However, it's also the case that the three counterexamples to EXERCISE-SUCCESS aren't such that the wider lessons from them can be satisfactorily explained by simply making the transition from EXERCISE-SUCCESS to FALLIBILISM.

After all, what unifies POLE VAULT, ENDER'S GAME and LINGUAPHILE SPY is the prima facie obtaining of the following three-part pattern:

(i) Exercise: a subject exercises an ability to $\phi$.

(ii) Failure: the subject does not successfully $\phi$

(iii) Success: the subject successfully $\psi \mathrm{s}$.

FALLIBILISM, to be clear, simply permits the conjunction in any given case of Exercise and Failure, a conjunction ruled out always and everywhere by EXERCISESUCCESS. That said, FALLIBILISM, in registering this permission, leaves unaccounted for how it is that the obtaining of Success should ever bear on the obtaining of Exercise when Exercise and Failure both hold. Put another way, what POLE VAULT, ENDER's GAME and LINGUAPHILE SPY indicate is that a satisfying account of ability exercise needs to go beyond simply (as the bare statement of FALLIBILISM does) articulating what ability exercise permits; it should also tell us how, exactly, one can exercise an ability to do one thing by doing some different thing.

Even more specifically, what the fallibilist needs to account for is this: when one $\psi$ s, one's $\psi$-ing constitutes an exercise of one's competence to $\phi$ if and only if what is the case? A positive proposal is needed here to supplement FALLIBILISM, and I turn now to offering such a proposal.

First, some new terminology will be needed: seat, shape, and situation. ${ }^{22}$ Following Sosa (e.g., 2010, 2015, Sosa 2017), let's stipulate that one possesses the seat of an ability (or competence, to use Sosa's terminology) to $\phi$ just in case one is internally constituted such that one would succeed reliably enough if one tried while (i) in proper shape and (ii) properly situated vis-à-vis $\phi$-ing. What counts as 'proper shape' and 'proper situation' in a given domain of endeavour are (as Sosa puts it) 'pre-selected' as those conditions where good performance in that relevant performance domain is principally valued. ${ }^{23}$

For example, in archery, we tend to value good performance in standard archery conditions-which involve being in the kind of shape that's appropriate to shooting an arrow (e.g., awake, alert) and being situated in an archery-relevant conditions (e.g., including, at least, the presence of a bow and arrow, ambient oxygen and lighting, wind conditions within normal bounds, etc.). While possessing the seat of an archery competence requires proper counterfactual safety (i.e., possessing the seat of an archery competence requires that one be reliable enough if one tried when one is in

\footnotetext{
22 Although Sosa, like other virtue epistemologists, does not think that exercising an ability is as Millar thinks a success notion, this point is independent of Sosa's specification of the structure of abilities. Put another way, it is open to one who embraces Sosa's account of the structure of abilities to either view the exercise of abilities as a success notion, or to deny this. I am making this point explicit so that it is clear that in adverting to Sosa's account of ability, I am not in doing so adverting to a position that precludes Millar's exercise-success thesis.

${ }^{23}$ For helpful discussion here, See Sosa $(2010,2015,2017)$.
} 
normal/proper shape-situation pairs, vis-à-vis archery), it importantly does not require either of the following: (i) proper counterfactual infallibility (i.e., that one be infallible if one tried when one is in normal/proper shape-situation pairs, e.g., alert, awake, equipped with bow and arrows, plenty of lighting, normal winds), nor (ii) abnormal counterfactual safety (i.e., that one be reliable enough if one tried when one is in abnormal/improper shape-situation pairs, e.g., drugged, underwater, supplied with broken arrows, deprived of oxygen, etc.)

The first point is especially important for our purposes. On a Sosa-style picture, it is precisely because ability possession doesn't require proper counterfactual infallibility that success is not implied by skillful performance. As Sosa (2015) puts it, a wellselected basketball shot might miss on a given occasion but still be skillful in so far as the shot issued from the exercise of a disposition that reliably enough hits the target (even if not from a disposition to always succeed) when in those conditions.

The more general idea here that falls out of Sosa's model is that what makes a given performance skillful or - as he puts it, adroit - (e.g., such that it manifests competence or ability) is not settled by asking whether the shot succeeded on that occasion or not, but rather, by asking whether it issued from the exercise of a disposition the exercise of which would not too easily have issued in failure when in conditions appropriate to that performance type. ${ }^{24}$

Against this background, we're now in a position to articulate a principle that, paired with FALLIBILISM, suffices to tell us in virtue of what one can exercise an ability to do one thing by doing some different thing. Call this further principle to supplement fallibilism Modal Coverage.

MODAL COVERAGE: When one $\phi$ s, one's $\phi$-ing constitutes an exercise of one's competence to $\psi$ if and only if in a wide enough class of near-by worlds where, holding fixed both the subject's seat and shape in her exercise of her competence to $\phi$ in the actual world, the situational conditions are the relevant ones to $\psi$-ing, and the subject attempts to $\psi$, that attempt is (non-deviantly) successful.

On the picture proposed, where in the actual world one $\phi$ s in shape/situation conditions relevant to $\phi$-ing, the worlds where one must be reliable enough at $\psi$-ing to count as exercising one's ability to $\psi$ by $\phi$-ing in the actual world are the nearest worlds to the actual world where one attempts to $\psi$, where the situation is relevant to $\psi$-ing, and we hold fixed that one is in the same seat and shape as one is in when $\phi$-ing in the actual world.

A pleasing consequence of supplementing FALLIBILITY with MODAL COVERAGE is that it offers plausible diagnoses of each of POLE VAULT, ENDER'S GAME and LINGUAPHILE SPY. Let's take them now in order.

Firstly, regarding POLE VAULT: with MODAL COVERAGE in play, the fallibilist can now account for why Paul exercises his ability to jump over the bar set at 10ft even when the bar isn't set at 10ft but rather at 13ft. Crucially, it's not that the ability to jump over a 13ft bar entails the former ability, nor for that matter that doing the latter thing entails that one has done or could do the former thing. Rather, the explanation is that in a wide class of near-by worlds where, holding fixed both seat and shape

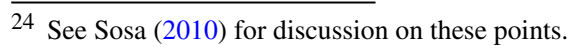


conditions vis-a-vis Paul's jump over the 13ft bar in the actual world, the conditions are the relevant ones for jumping over the bar set at 10ft (i.e., the bar actually is set to $10 \mathrm{ft}$ rather than to $13 \mathrm{ft}$ ), and Paul attempts ${ }^{25}$ to jump over the bar set at $10 \mathrm{ft}$, not too easily in those conditions would that attempt have not been (non-deviantly) successful. (After all, in these worlds, Paul sails easily over the 10ft bar, indeed, easier than he did over the $13 \mathrm{ft}$ bar in the actual world).

Likewise, in ENDER'S GAME: when Ender directs a winning (non-simulated) battle in the real world, his doing so constitutes an exercise of his competence to direct a winning simulated battle because, in a suitably wide class of near-by worlds where, holding fixed that Ender retains the seat and shape conditions relevant to directing the winning battle in the actual world, the conditions are the relevant ones to directing ceteris paribus a simulated battle, and Ender attempts to direct a winning simulated battle, not too easily in those conditions would that attempt have not been successful (viz., his attempt would have been safe). The nearest worlds, after all, are just worlds where Mazer leaves things as usual and doesn't switch the simulator out for a real battle. $^{26}$

Finally, in the case of LINGUIPHILE SPY: when George skilfully averts his eyes from what he can tell are Basque words to gibberish, his doing so constitutes an exercise of his competence to understand Basque words for the following reason: in enough nearby worlds in which George retains the seat and shape conditions relevant to his tricking his interrogators in the actual world, the conditions are the relevant ones to understanding Basque words (e.g., Basque words are present but there is no incentive not to read them), and were George to attempt to understand them, he would fairly easily succeed.

\section{Objections and replies}

Objection But wait, on the view proposed, someone can count as exercising an ability to do something without even trying or intending to exercise that ability, or for that matter, without even thinking about doing the thing that the ability is an ability to do. For example, it looks like the view must allow that when a professional bowler bowls a strike, that in doing so, she thereby exercises her ability to knock over a water glass placed three feet from her. But this is problematic, right?

\footnotetext{
25 Note that the role of 'attempts' in this formulation perfectly compatible with the claim that one can exercise an ability without doing so intentionally (i.e., as per Vetter's point), or for that matter, without making any intentional attempt.

26 Additionally, the proposed model can accommodate the intuition that (for instance) Ender is really exercising his simulation-war-winning ability by directing a non-simulated battle, and thus that he is not merely such that (as an anticipated objection might go) he would or could easily have exercised such an ability under different circumstances (e.g., if he were in a simulated battle rather than the real one he happens to be placed in). The reason that the proposed view can straightforwardly deal with this objection is because, it is important to stress, the seat and shape that form the material base of Ender's ability (i.e., inner-most competence) to direct a simulated battle (e.g., his innermost cognitive and manual skills that correspond with certain parts of his brain and muscles, etc.) are actually featuring causally in Ender's direction of the non-simulated battle when he is directing it (i.e., his inner-most competence to direct a simulated battle is not lying dormant while he directs the non-simulated battle, which is as it should be).
} 
Reply This implication turns out to be a virtue of the proposal rather than a vice. Here's why. Assume, for reductio, that one can exercise an ability only if one tries to exercise that ability, where this minimally involves forming an intention to do the thing in question. If such a thing were a necessary condition on exercising an ability, then we'd immediately run into the kinds of worries Vetter (2016) raises for views that explicitly include such a requirement, such as Moore's and Vihvelin's. In particular, we'd lack a way to make sense of how we seem to exercise abilities ubiquitously in cases of complex action and subintentional action (see Sect. 4). The lesson from considering Vetter's objections to such proposals is that we should not assume that exercising ability involves intention, even if ability exercise often involves intention. But if that's right, then it's no problem for the proposal I'm advancing that it is not committed to this (problematic) assumption.

Objection The account, though, ends up being inclusive regardless of whether ability exercise essentially involves intention. Is it the case that whenever I raise my eyebrows in the relevant way in order to signal disapproval I have exercised my ability to annoy my father? If we suppose the ability to signal disapproval and the ability to annoy my father by raising my eyebrows plausibly have a shared seat and shape, it looks like, on the proposed account, the answer may well be 'yes'. Though, this is a highly counterintuitive result.

Reply I agree that this is an initially counterintuitive implication of the view. For example, if I raise my eyebrow to signal disapproval at something I've seen on the news, it seems odd to say that in doing so I've exercised my ability to annoy my father, especially when he is not there to annoy. ${ }^{27}$ There is, however, available a straightforward Gricean explanation for the counterintuitiveness. Often times (as is an implication of the view defended here) we in fact exercise multiple abilities at once. The Gricean maxims (in particular, quality and quantity) tell us that not all such abilities will be conversationally relevant. For this reason, drawing attention to the exercise of such abilities when they are not conversationally relevant violates such maxims.

Objection But if I'm exercising my abilities all the time in these cases where I don't intend to succeed, the reliability for all abilities will be dangerously low-plausibly below the threshold. And this is problematic because the reliability of an ability to $\phi$ should not be affected by cases where I don't even intend to $\phi{ }^{28}$ For example, the reliability of my ability to annoy my father shouldn't be affected in cases where I don't annoy my father but count as exercising my ability to annoy him by raising my eyebrows.

Reply The above worry would be troubling for my proposal if the relevant reference class with reference to which the reliability of an ability is to be assessed is identical to the class of cases in which that ability is exercised. For then, for example, Ender's defeating real-life opponents but not simulated opponents by exercising his ability to defeat simulated opponents (e.g., as in ENDER's GAME) would actually count against the reliability of his ability to defeat simulated opponents since (on this occasion) he exercised his ability to defeat simulated opponents but didn't actually defeat any.

\footnotetext{
27 Thanks to Christoph Kelp for helpful discussion.

28 Thanks to an anonymous referee at Synthese for raising this objection.
} 
In response to this worry, I want to emphasise that my proposal is simply not committed to regarding the reference class with reference to which the reliability of an ability is assessed as identical to the class of cases in which that ability is exercised. What's more, there's already good reason to think my proposal will (when it comes to assessing the reliability of an ability) be committed to identifying a different reference class on this score. Here it is helpful to recall (from Sect. 3) that the view advanced is one on which ability possession is itself a matter of counterfactual safety in the following sense: possessing an ability requires being such that you would succeed safely enough if you tried in appropriate conditions. The relevant reference class with respect to which reliability matters for ability possession is accordingly just the class of cases in which one tries while when in proper shape and properly situated. Accordingly, there is a principled reason for thinking that the account of ability possession upon which my proposed account of ability exercise is predicated upon is not such that it would succumb to the kind of reliability worry canvassed above.

\section{Concluding remarks}

It might seem initially platitudinous that one exercises an ability to do something only when one successfully does what the ability is an ability to do. This thesis underwrites Millar's distinctive epistemology of perception (according to which perceptual recognitional abilities are exercised only when one comes to acquire knowledge), though it can be fruitfully evaluated entirely outwith the context of the epistemology of perception, as a general thesis about ability exercise. In this paper, I've challenged this general thesis about abilities and their exercise conditions and have argued for an alternative view, one that is grounded in sound insights about the structure of abilities, avoids various technical problems facing views on which ability exercise is a success notion, and which neatly explains why it is that in various kinds of cases discussed, we can intuitively exercise an ability to do one thing by in fact doing something else. ${ }^{29}$

Open Access This article is distributed under the terms of the Creative Commons Attribution 4.0 International License (http://creativecommons.org/licenses/by/4.0/), which permits unrestricted use, distribution, and reproduction in any medium, provided you give appropriate credit to the original author(s) and the source, provide a link to the Creative Commons license, and indicate if changes were made.

\section{References}

Card, O. S. (1985). Enders game. New York: Tor Books.

Chrisman, M. (2012). The normative evaluation of belief and the aspectual classification of belief and knowledge attributions. The Journal of Philosophy, 109(10), 588-612.

Ericsson, A., \& Pool, R. (2016). Peak: Secrets from the new science of expertise. Boston: Houghton Mifflin Harcourt.

Fitts, P. M., \& Posner, M. I. (1967). Human performance. Oxford: Brooks/Cole.

\footnotetext{
29 Thanks to three anonymous referees at Synthese for very helpful comments on previous versions of this paper. I'm also grateful to Emma C. Gordon, Christoph Kelp, Neil McDonnell and Peter Graham for helpful discussion. A special thanks to Alan Millar for numerous valuable discussions about these issues, and for originally piquing my interest in the topic.
} 
Glazier, P. S., \& Davids, K. (2009). Constraints on the complete optimization of human motion. Sports Medicine, 39(1), 15-28.

LeCarre, J. (1974). Tinker Tailor Soldier Spy. London: Hodder \& Stoughton.

McKitrick, J. (2010). Manifestations as effects. In A. Marmodoro (Ed.), The metaphysics of powers: Their grounding and their manifestations (pp. 73-83). New York: Routledge.

Millar, A. (2009). What is it that cognitive abilities are abilities to do? Acta Analytica, 24(4), 223-236.

Miracchi, L. (2015). Competence to know. Philosophical Studies, 172(1), 29-56.

Moore, G. E. (1911). Ethics. Oxford: Oxford University Press.

Mourelatos, A. (1978). Events, processes, and states. Linguistics and Philosophy, 2(3), 415-434.

Pearce, K. (2012) Omnipotence. Internet Encyclopedia of Philosophy.

Rohrbaugh, G. (2015). Inner achievement. Erkenntnis, 80(6), 1191-1204.

Sosa, E. (2009). A virtue epistemology: Apt belief and reflective knowledge (Vol. 1). Oxford: Oxford University Press.

Sosa, E. (2010). How competence matters in epistemology. Philosophical Perspectives, 24(1), 465-475. https://doi.org/10.1111/j.1520-8583.2010.00200.x.

Sosa, E. (2015). Judgment and agency. Oxford: Oxford University Press.

Sosa, E. (2017). Epistemology. Princeton: Princeton University Press.

Steward, H. (2012). A metaphysics for freedom. Oxford: Oxford University Press.

Vendler, Z. (1957). Verbs and times. The Philosophical Review, 66, 143-160.

Vetter, B. (2016). Are abilities dispositions? Synthese, 10, 1-20. https://doi.org/10.1007/s11229-016-11527.

Vihvelin, K. (2004). Free will demystified: A dispositionalist account. Philosophical Topics, 32, 427-450.

Williams, J. N. (2008). Propositional knowledge and know-how. Synthese, 165(1), 107-125.

Publisher's Note Springer Nature remains neutral with regard to jurisdictional claims in published maps and institutional affiliations. 